\title{
A systematic review of the factors - enablers and barriers - affecting e-learning in health sciences education
}

Krishna Regmi ${ }^{1,2^{*}}$ and Linda Jones ${ }^{2}$

\begin{abstract}
Background: Recently, much attention has been given to e-learning in higher education as it provides better access to learning resources online, utilising technology - regardless of learners' geographical locations and timescale - to enhance learning. It has now become part of the mainstream in education in the health sciences, including medical, dental, public health, nursing, and other allied health professionals. Despite growing evidence claiming that e-learning is as effective as traditional means of learning, there is very limited evidence available about what works, and when and how e-learning enhances teaching and learning. This systematic review aimed to identify and synthesise the factors - enablers and barriers - affecting e-learning in health sciences education (el-HSE) that have been reported in the medical literature.
\end{abstract}

Methods: A systemic review of articles published on e-learning in health sciences education (el-HSE) was performed in MEDLINE, EMBASE, Allied \& Complementary Medicine, DH-DATA, PsycINFO, CINAHL, and Global Health, from 1980 through 2019, using 'Textword' and 'Thesaurus' search terms. All original articles fulfilling the following criteria were included: (1) e-learning was implemented in health sciences education, and (2) the investigation of the factors - enablers and barriers - about el-HSE related to learning performance or outcomes. Following the PRISMA guidelines, both relevant published and unpublished papers were searched. Data were extracted and quality appraised using QualSyst tools, and synthesised performing thematic analysis.

Results: Out of 985 records identified, a total of 162 citations were screened, of which 57 were found to be of relevance to this study. The primary evidence base comprises 24 papers, with two broad categories identified, enablers and barriers, under eight separate themes: facilitate learning; learning in practice; systematic approach to learning; integration of e-learning into curricula; poor motivation and expectation; resource-intensive; not suitable for all disciplines or contents, and lack of IT skills.

Conclusions: This study has identified the factors which impact on e-learning: interaction and collaboration between learners and facilitators; considering learners' motivation and expectations; utilising user-friendly technology; and putting learners at the centre of pedagogy. There is significant scope for better understanding of the issues related to enablers and facilitators associated with e-learning, and developing appropriate policies and initiatives to establish when, how and where they fit best, creating a broader framework for making e-learning effective.

Keywords: Health sciences, E-learning, Barriers, Enablers, Widening participation, Lifelong learning

\footnotetext{
* Correspondence: Krishna.r.regmi@gmail.com

${ }^{1}$ Faculty of Health and Social Sciences, Institute for Health Research,

University of Bedfordshire, Luton LU2 8LE, UK

${ }^{2}$ Centre for Medical Education, School of Medicine, University of Dundee,

The Mackenzie Building, Kirsty Semple Way, Dundee DD2 4BF, UK
}

(c) The Author(s). 2020 Open Access This article is licensed under a Creative Commons Attribution 4.0 International License, which permits use, sharing, adaptation, distribution and reproduction in any medium or format, as long as you give appropriate credit to the original author(s) and the source, provide a link to the Creative Commons licence, and indicate if changes were made. The images or other third party material in this article are included in the article's Creative Commons licence, unless indicated otherwise in a credit line to the material. If material is not included in the article's Creative Commons licence and your intended use is not permitted by statutory regulation or exceeds the permitted use, you will need to obtain permission directly from the copyright holder. To view a copy of this licence, visit http://creativecommons.org/licenses/by/4.0/. The Creative Commons Public Domain Dedication waiver (http://creativecommons.org/publicdomain/zero/1.0/) applies to the data made available in this article, unless otherwise stated in a credit line to the data. 


\section{Background}

There are different meanings or interpretations of e-learning, but employing the technology to provide online access to learning resources for the improvement of learning is its principal aspect $[1,2]$. E-learning has been defined as "an educational method that facilitates learning by the application of information technology and communication providing an opportunity for learners to have access to all the required education programmes" [3]. The term e-learning has been interchangeably used with the terms web-based learning, online learning or education, computer-assisted or -aided instruction, computer-based instruction, internetbased learning, multimedia learning, technology-enhanced learning and virtual learning $[4,5]$. Such nomenclature has led to confusion as to whether e-learning is part of the medium (e.g. computer-assisted instruction) or the delivery mechanism (e.g. online learning).

There are different models or designs of e-learning which have been used in practice, the most common of which are: (a) enhanced or adjunct model - acts as an assistant in classroom face-to-face learning, providing relative independence to the students; (b) blended elearning model - integration of classroom face-to-face learning experiences with online learning; and (c) pure online or fully-online model - without classroom or traditional face-to-face learning, to provide maximum independence to the students. This model can be further divided into individual and collaborative learning, with the collaborative learning option being sub-divided into synchronous (face-to-face) and asynchronous (text-based internet) $[6,7]$.

Similarly, there are different components of e-learning; for example, Ruiz et al. [5] describe three components: (a) development of content; (b) management of the content; and (c) delivery of the content in a synchronous or asynchronous way. Ruggeri et al. [8] highlight four components: (a) synchronicity (asynchronous vs synchronous); (b) location (same place vs distributed); (c) independence (individual vs collaborative); and (d) mode (electronic-only vs blended). Cook [9] also proposes four components: (a) mode of delivery of contents (e.g. textbook, face-to-face, computer-based, television); (b) configuration, i.e. differences within a given media format (e.g. web-based discussion board vs face to face, small-group discussion, lecture); (c) instructional method (e.g. learning activities, self-assessment questions, clinical cases); and (d) presentation (e.g. hyperlinks, multimedia, font simulation fidelity).

Recently, e-learning has been well recognised as mainstreaming in health sciences education (HSE) - medical, dental, public health, nursing, and other allied healthcare education - but the role of e-learning and its effect on learners' performance or enhancing their learning has been well debated. E-learning, however, has had less impact than intended, and HSE practices have remained largely unchanged over the past decade. Cook et al. [4] raise some concerns over whether e-learning in medical education or el-HSE would actually enhance learning, particularly "the extent to which knowledge-based learning compared with alternative approaches to medical education".

Though some published systemic reviews on elearning have provided some promises that e-learning would be equally as effective as traditional methods of learning or teaching, still there is very limited evidence demonstrating when and how best e-learning enhances education and learning, and the factors associated with it [4, 10-14]. As Kim [15] argues, most of the published evidences, including the systematic reviews on elearning, appear to have three major limitations: (a) they are mostly descriptive; (b) they have clearly failed to demonstrate the outcome measures; and (c) the majority have faults due to weakness or inappropriateness in study designs.

Another systematic review, capturing 176 empirical studies, conducted between 1996 and 2008, shows "students in online conditions performed modestly better, on average than those learning the same material through traditional face-to-face instruction" [16]. These interpretations, however, should be treated with caution, as the conditions and dimensions for both methods are not the same, particularly the learners' and facilitators' time spent on setting or accomplishing tasks, level of accessibility, and convenience [4, 17].

Two recent systematic reviews conducted by $\mathrm{Du}$ et al. [18] with nine RCTs, and Lahti et al. [19] with 11 RCTs, examined the effects of e-learning or web-based nursing education, but the findings reported were not significantly different between these two methods (e-learning and traditional education) as they reported almost similar results or slight improvements in knowledge, mainly on learners' levels of satisfaction associated with e-learning. A Cochrane Review including 16 randomised trials (involving 5679 health professionals), published in 2018, examining the effects of e-learning versus traditional learning, reported little or no differences in patient outcomes or health professionals' skills and behaviours [20].

Similarly, several studies make claims for e-learning and learning enhancement, but the results appeared rather mixed [4, 21, 22]. It has been found that if we simply compare the outcomes between e-learning and no training interventions, e-learning is generally far more effective in gaining knowledge, skills including positive behaviours, but this does not necessarily mean that the results are significant mainly due to the fact that results are heterogeneous (i.e. inconsistent results) and are frequently in small studies [23, 24].

Ellaway and Masters [25] also argue that "despite several decades of research and development in and around 
the use of computers in education, its practices and techniques are fluid and subject to change for more than other aspects of healthcare education". However, strong evidence of el-HSE and its expectations and the factors - enablers and challenges - concerning e-learning is rather limited, scattered and patchy $[15,22,26]$.

First, some evidence is available about the examining of e-learning from knowledge and attitudes of learners, but very limited evidence exists on the "impact of e-learning on learning outcomes" [27]. Second, limited studies have been published measuring e-learning and its effectiveness on education performance $[22,28]$. Cook and McDonald [29] state that in e-learning, several questions have not yet been answered; for example, "what are the elements of effective e-learning in health sciences education (el-HSE), effective design and how do these vary for learners at different levels", and there was no single paper published "on how to develop and implement e-learning interventions" effectively, as some forms of methodological innovation are required in education and learning to develop learners' knowledge and skills both in academic and practice environments [13]. Third, recent research based on 72 studies also reported the lack of good research available on elearning, and they pointed out that: "no studies have investigated e-learning in medical education (also in el-HSE) in a systematic way or with a focus on specific practice areas" [30].

In addition, several studies equally failed to capture the wider aspects of e-learning, exploring policy drivers, learning content, pedagogy methods, variability in designs and instructional methodologies, quality standards, or educational theories or principles [31,32]. Though some studies have compared e-learning with traditional approaches of teaching/learning, results appeared conflicting and inconclusive [10,33].

This systematic review, therefore, aimed to identify and synthesise the factors - enablers and barriers - affecting e-learning in health sciences education (el-HSE) that have been reported in the medical literature.

\section{Methods}

This study utilised a systematic literature review (SLR) method. SLR is considered a valuable form of research, which also closely follows the principles of scientific methods, through being "designed to locate, appraise and synthesise the best available evidence" in relation to the research purpose, to be able to provide "informative and evidence-based" research [34].

\section{Search strategy}

A systematic search for articles published on el-HSE was performed in MEDLINE, EMBASE, Allied \& Complementary Medicine, DH-DATA, PsycINFO, CINAHL, and Global Health, from 1980 through 2019. Primary search terms were e-learning (all synonyms) and health sciences education (all synonyms) using 'Textword searching' - searching for a word or phrase appearing anywhere in the document, where the document is the citation (article title, journal name, author), not the full text of an article, and 'Thesaurus (MeSH, EMTREE) searching', employing Boolean operators and truncations, such as ("e-learning" OR "online learn"” OR "distance learn" " OR "computer-assisted instruction" OR "web-based learning" OR "internet-based learning" OR "multi-media learning" OR "technology-enhanced learning" OR "distributed learning" OR "virtual patients" OR "virtual microscopy" OR "virtual environment" OR "virtual learning") AND ("continuing medical education" OR "medical education" OR "health sciences" OR "basic Sciences" OR "public health education" OR "nursing education" OR "public health nursing" OR "allied health education") AND ("challenges" OR "barriers" OR "enablers" OR "facilitator"). A detailed systematic review protocol, developed by the authors, with specific search terms has been provided in the Additional file 1.

\section{Inclusion and exclusion criteria}

All original research articles on e-learning fulfilling the following eligibility criteria were included:

- e-learning was implemented in health sciences education

- the investigation of the enablers and barriers about el-HSE related to learning performance or outcomes

- articles were published in peer-reviewed journals, in English, after 1980.

\section{Exclusion criteria were:}

- articles falling outside e-learning in health sciences education

- articles published in secondary, non-empirical studies or grey literature

- commentaries, review documents, case studies, letters, discussion papers, posters, conference abstracts, congress reports and dissertations

- articles not published in peer-reviewed journals

- no full text available.

\section{Selection of studies}

The citations identified through the searches was imported into Refworks software (https://www.refworks. $\mathrm{com} /$ ). The literature which emerged from the databases, snowballing and hand-searching has been screened at two stages: first, a review of abstracts and titles of the retrieved literature to see whether they meet minimum inclusion criteria. Second, the full text of the included articles was reviewed and retrieved using a critical 
appraisal tool [35]. As Means et al. [16] argue, "the intent of the two-stage approach was to gain efficiency without risking exclusion of potentially relevant, highquality studies of online learning effects". The standard PRISMA flowchart has been used to provide the process of study selection [36] (Fig. 1).

\section{Data analysis and synthesis}

Based on the final search outputs, 24 papers were identified to fit in the review, and they were mostly quantitative in nature. As Clarke [37] argues, when such heterogeneity in methodology exists, "systematic review does not need to combine the results of the studies to provide an average estimate". Therefore, in this study, data were synthesised through narrative synthesis using thematic analysis (TA) [38]. TA has been considered as "a method [ ...] identifying, analysing and reporting patterns (themes)" or meaning searching across the literature or data [39]. In this study, to identify the recurrent themes we followed these six steps when synthesising data using thematic analysis, e.g. familiarising with the data, developing initial (sub) codes, searching for (sub) themes, reviewing (sub) themes, charting or compiling ideas or issues, and producing final data in line with the study aims and objectives $[40,41]$.

\section{Tabulating the included studies}

We developed a table to capture the nature of the studies (designs, methods and populations, see Table 2). To ensure the accuracy and completeness of the data extraction by KR, data extraction was checked by LJ. As Petticrew and Roberts [65] confirm, this would not only improve the process of transparency by better understanding what sorts of "data have been extracted from which studies", but also recognising the "contribution made by each study to the overall synthesis".

\section{Quality assessment}

Methodological quality of the included studies was assessed with the 'QualSyst developed by Kmet and colleagues [35], and we particularly found its scoring system useful because it has clearly shown the process to be more "systematic, reproducible and quantitative means of assessing the quality" of those retrieved papers [66]. There are checklists of 14 question items for assessing quantitative and 10 questions for qualitative studies,

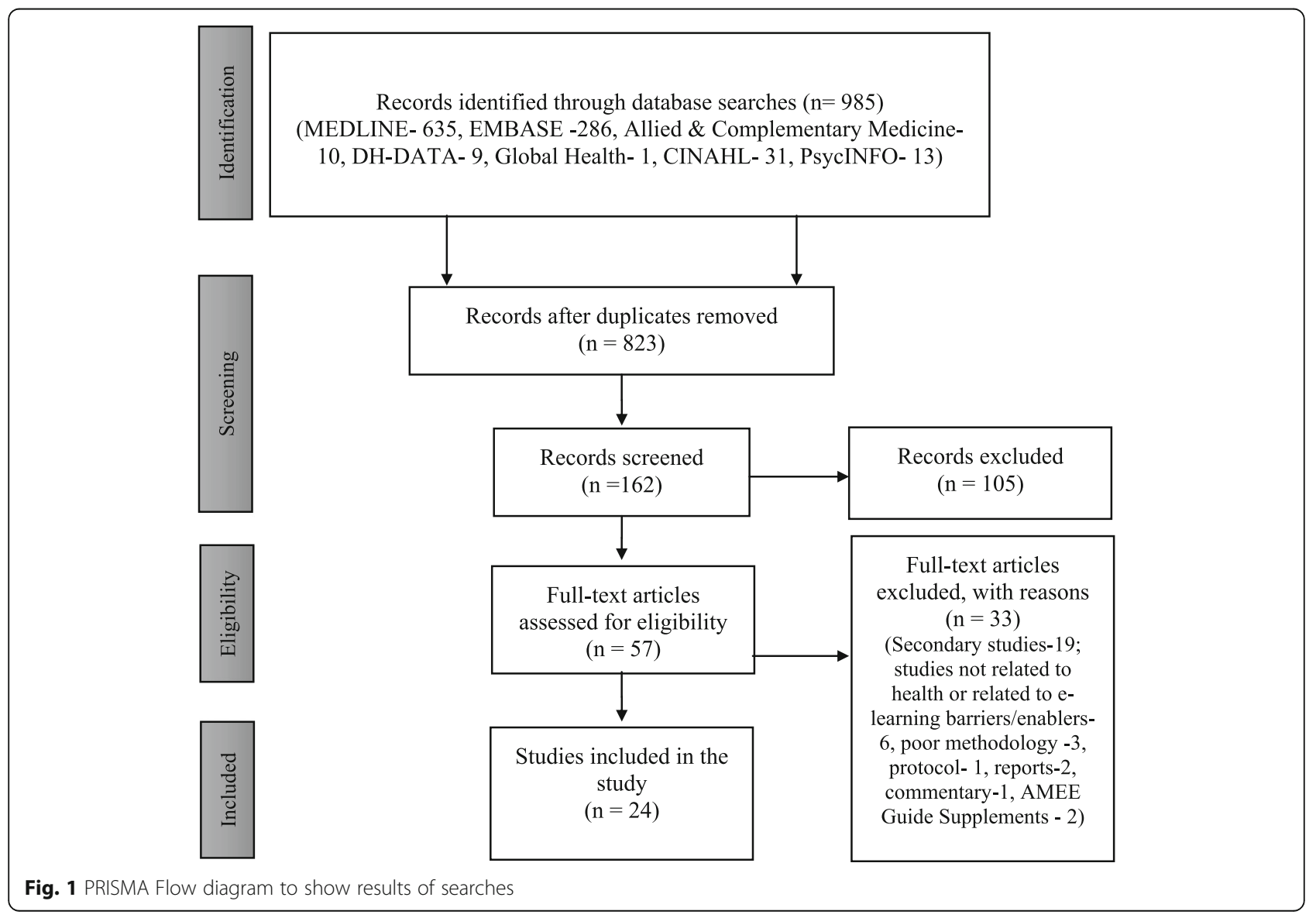


and a score of $0-2$ has been awarded to each item, with a final score calculated by summating the total score across the items and dividing them by the total possible sum (e.g. 28 for quantitative and 20 for qualitative studies) [66, 67]. A cut-off of $75 \%$ as the threshold for quantitative, and $55 \%$ for qualitative papers has been set up. For mixed methods studies, specifically designed questions were employed to assess the quality [67]. Complete details regarding quality appraisals of individual studies were provided in the Additional file 2.

\section{Results}

Out of 985 records identified, a total of 162 citations were screened, of which 57 were found to be of relevance to this study. The primary evidence base comprises 24 papers; most were quantitative $(14,58.33 \%)$ in design (see Fig. 1). Most studies were published between 2005 and 2019. This is based on approximately 2355 participants, who were mostly undergraduate and postgraduate students or learners $(1831,77.74 \%)$. The geographical range of papers covered mostly the highincome regions. Detail information regarding the demographic profile of included articles are presented in Table 1. A summary of excluded studies and reasons for exclusion are provided in the Additional file 3.

Upon conducting thematic analysis of the included studies, it was possible to obtain two broad descriptive themes/categories: enablers or drivers of, and barriers or challenges to, el-HSE, under which eight important themes have emerged.

\section{Enablers or drivers}

- Theme 1. Facilitate learning

- Theme 2. Learning in practice

- Theme 3. Systematic approach to learning

- Theme 4. Integration of e-learning into curricula

\section{Barriers or challenges}

- Theme 5. Poor motivation and expectation

- Theme 6. Resource-intensive

- Theme 7. Not suitable for all disciplines/contents

- Theme 8. Lack of IT skills

\section{Enablers or drivers}

\section{Theme 1: Facilitate learning}

Seventeen out of 24 studies reported that e-learning has been one of the successful approaches and tools to facilitate the process of learning amongst healthcare professionals in practice $[3,42,43,45,46,48,50-53,55-59$, 61, 62]. Several studies highlighted that e-learning has been influenced mostly by structured frameworks in the way it is contextualised, builds in the learners'
Table 1 Demographic profile of included studies

\begin{tabular}{|c|c|}
\hline Study characteristics & Number of studies (\%) \\
\hline \multicolumn{2}{|l|}{ Year of publication } \\
\hline • 2005-2008 & $7(29.16 \%)$ \\
\hline • 2009-2012 & $5(20.83 \%)$ \\
\hline • 2013-2015 & $6(25 \%)$ \\
\hline • 2016-2019 & $6(25 \%)$ \\
\hline \multicolumn{2}{|l|}{ Type of study } \\
\hline - Quantitative & $14(58.33 \%)$ \\
\hline - Qualitative & $7(29.16 \%)$ \\
\hline - Mixed methods & $3(12.5 \%)$ \\
\hline \multicolumn{2}{|l|}{ Study sample } \\
\hline - 50 and $<$ & $8(33.33 \%)$ \\
\hline$\cdot$ • 50-100 & 7 (29.16\%) \\
\hline$\cdot 100-150$ & 5 (20.83\%) \\
\hline$\cdot 150-200$ & - \\
\hline$\cdot 200-250$ & $1(4.16 \%)$ \\
\hline$\cdot 250-300$ & $1(4.16 \%)$ \\
\hline$\cdot 300-350$ & $1(4.16 \%)$ \\
\hline - 350 and > & $1(4.16 \%)$ \\
\hline \multicolumn{2}{|l|}{ Countries } \\
\hline - Australia & $2(8.33 \%)$ \\
\hline - Belgium & $1(4.16 \%)$ \\
\hline - Brazil & $1(4.16 \%)$ \\
\hline - Canada & $1(4.16 \%)$ \\
\hline - Germany & $1(4.16 \%)$ \\
\hline - Iran & $2(8.33 \%)$ \\
\hline - Netherlands & $2(8.33 \%)$ \\
\hline • Norway & $1(4.16 \%)$ \\
\hline - Slovenia & $1(4.16 \%)$ \\
\hline - Spain & $1(4.16 \%)$ \\
\hline - Sweden & $1(4.16 \%)$ \\
\hline$\cdot$ UK & $6(25 \%)$ \\
\hline - USA & $3(12.5 \%)$ \\
\hline - Pakistan & $1(4.16 \%)$ \\
\hline
\end{tabular}

experience, and aligns with course assessments or learning outcomes $[45,50,56]$.

In addition, it develops appropriate interaction between and amongst learners and facilitators that would enhance learning by making it more integrated and contextualised, with the possibility of bringing learners a high level of exciting and stimulating learning [46, 50]. The following two extracts illustrate this:

E-learning provides the opportunity for instructors or teachers to teach better, since it allows them to 
use a range of both technical and pedagogical teaching tools [62].

Integrated, clinically-oriented interdisciplinary learning that focuses on knowledge and skills to encourage "learning through doing" is an important attribute of online e-learning [46].

Studies also noted that when learners wish to learn in a more in-depth way about the practice or the context, then e-learning would be a preferred approach to learning as it considers four components - content, educator, system, and learners - which might play an important part in making e-learning effective $[45,50,53]$. It has now become an accepted tool or approach for continuing professional development (CPD), mainly among medical, nursing and allied healthcare professionals, as the nature of e-learning often benefits from contemporary information, delivered rapidly and flexibly, adopting varying formats $[61,62]$.

Flexibility in nature means that learning often takes place at the learners' own pace, regardless of their geographical locations, and materials can be accessed any time, and these are reported as perceived benefits or key enablers compared with lecture mode [42, 46, 51, 52]. The extracts below highlight very clearly the strong support to the flexibility aspect of e-learning:

I think online also you kind of get a more in-depth amount of information because you can read it yourself at your own time rather than having to fit a certain amount of information into like a one-hour, two-hour lecture. You can spend like half an hour blocks trying to get that information. So it's all [set] out there for you and it's really well explained, whereas someone in a lecture has only a certain amount of time to kind of go over it ... and with less detail than what you can get online [46].

\section{Theme 2: Learning in practice}

Fifteen out of 24 studies included in this review reported that e-learning had been found an effective approach regarding the transformation of knowledge-integration into practice through education and training, including CPD in healthcare settings [42-44, 46-57, 59]. A study conducted among 148 GPs, using exploratory factor analysis, has highlighted that the intention of using el-HSE was mainly due to its widely accepted and preferred method in practice [49]. Similarly, Morente et al.'s [57] study conducted among nursing students has also reported that e-learning has improved educational efficacy and better learning acquisition.

Several studies further showed that e-learning is the most effective approach for transferring clinical skills and knowledge, using virtual clinical case studies adopting a mixed learning approach, combining different styles and modes not only to facilitate learning but also to bring positive change in practice $[47,53-55]$. Therefore, the integration of theoretical learning into practice using el-HSE is evident $[44,47,53,56]$.

Six out of 24 papers highlighted that developing learners' motivation, satisfaction, expectation, training and support needs were the key reported factors for improving working practice $[42,43,46,48,54,58]$. Similarly, they also noted that effective information and education support, ease of access, inter-professional learning, learning appropriately, integrating and applying learners' values and skills acquisition into practice were consistently highlighted in the retrieved papers as successful for bringing positive impacts on work and opportunities to learn. Gormley et al.'s [48] survey conducted amongst undergraduate medical students, assessing the effectiveness of elearning in clinical skills, also demonstrated that learners found e-learning particularly useful as learners would be able to access and review e-learning materials before their learning. Second, it also "encouraged them to see real patients through uploading relevant online videos of particular use which appeared as one of the important domains in their learning" [48]. The relevant extract below highlights the support of e-learning:

This method [e-learning] of teaching as being a good way to address sensitive consultations, important issues and bringing attention to situations [even] they [students] may not have encountered [51].

\section{Theme 3: Systematic approach to learning}

Eleven out of 24 papers showed that el-HSE is a superior approach to classical or traditional learning in terms of improving quality of education through integrating theoretical contexts into practice [3, 42-44, 48, 49, 51, 55, $56,58,59]$. Accompanying these thoughts, a recent study conducted among undergraduate healthcare students using a mixed-methods approach reported that the nature of e-learning often adopts some systematic approach to learning, i.e. moving from simple to complex learning, arguing that ideas or knowledge are logical and interconnected for the consolidation of learning, from the holistic perspective, to meet the learning goals [58]. Such a process would also help to create a social construction of knowledge [59].

As e-learning involves multidisciplinary uses, creativity, motivation, quality and accessibility, it provides an alternative education approach or opportunity for lifelong learning, addressing both the long-term and shortterm healthcare and education goals of learners [3, 43, $44,50,55,56]$. It has also been reported that the effectiveness of e-learning would be determined by the extent 
to which learners' short-term and long-term personal and professional educational needs are met $[3,49,55]$.

Similarly, several authors reported that in a new era, the traditional style of teaching and learning is getting out-ofdate, so e-learning would be an appropriate means and end for lifelong learning, mainly due to its nature of flexibility in education and learning $[48,56,58,59]$.

\section{Theme 4: Integration of e-learning into curricula}

Six out of 24 studies reported some pedagogic issue associated with learning methods and styles $[44,47,50,55$, $56,64]$. Curriculum and pedagogy are interlinked by two different approaches (models), e.g. blended learning and flipped classroom as they present some degree of the interface between learners and philosophy of the learning. Blended learning intervention is simply integration of classroom face-to-face learning experiences with online learning to facilitate independent, interactive and collaborative learning due to its flexible and technologically rich format. This approach is, however, reported as complex and challenging in nature due to its different possible designs, and contextual needs. Flipped or inverted classroom is a form of blended learning, where students learn in part in class, and in part through online learning, providing students more choices in terms of the place and pace of learning experiences. The key factors for success in these models of e-learning or online education are to collaborate and integrate e-learning into current curricula $[51,55]$.

Several studies also reported that engagement in e-learning among learners and professionals, mainly from HSE, is useful and has positively impacted engagement and retention of learning $[50,58,63]$. The extracts below illustrate this:

The success for medical educators is to ensure engagement with the online self-directed component of the module. This initial learning should allow students to fill in the gaps in their knowledge by focusing them on what they do not know, which may enhance retention [58].

Accompanying these issues, four papers have consistently reported that contacts (with learners and facilitators), opportunities for self-assessment, flexibility, and faster and easier access to quality learning resources are equally important dimensions or approaches that would enhance students' interest in learning and improve both their level of engagement and their learning autonomy $[3,44,50,56,64]$.

\section{Barriers or challenges}

\section{Theme 5: Poor motivation and expectation}

Seven out of 24 papers reported factors that may be variants to learners' motivation and expectations to be able to meet their personal and professional needs and goals $[44,45,47,50,55,56,60]$. While analysing reported factors, two groups of factors appeared common, i.e. internal and external factors. Internal factors refer to the poor engagement, poor perception and motivation, limited flexibility, high levels of anxiety and stress, lack of students' self-discipline and low self-efficacy, as well as poor interactions between learners and facilitators. Such factors not only hinder the process of learning and motivation but also fail to meet learners' healthcare needs and expectations [44, 45, 47, 56].

External factors are mostly related to the course structure, poor pedagogical design, clarity of the purpose and goal, education management policy, educational paradigms, learners' diversity, current and future education workforce needs, financial independence, influence of national and international policies, lack of learning space, limited use of technology in education, poor evidence-based education and training, and strategic change in higher education as well as inadequate support $[3,45,48,50,52,53,562-58,65]$.

\section{Theme 6: Resource-intensive}

Nine out of 24 papers included in this review have reported that e-learning is a time-, cost- and labourintensive approach $[44,45,47,50,53,55,56,60,63]$. Several papers also raised the technological or IT challenges, as several learners are not familiar with e-learning and in some contexts, even basic IT knowledge and skills are lacking $[44,45,53,55,56,63]$. Thus, inappropriate equipment and technological illiteracy have raised some concerns with regard to the usefulness of el-HSE [59].

Both Hammarlund et al. [50] and Ikram et al. [53] also highlighted that issues related to long-term costs and resources raised concerns related to quality, usability and effectiveness, poor consideration of users' needs, lack of time, and lack of students' self-discipline, all of which would have a negative impact on e-learning.

\section{Theme 7: Not suitable for all disciplines or contents}

Eight out of 24 papers reported that integration of learning into the existing curricula would be problematic, as some disciplines, for example, biomedical, would take extensive time for learners and facilitators to adapt the content into e-learning curricula $[44,46,50,51,55,56,59]$.

Additionally, several papers have reported that in elearning, not only might some content not be suitable as these disciplines need practical or demonstrative types of learning, but also this creates some problems of communication, as well as a lack of group dynamics [44, 47, 50, 55]. The extract below illustrates this:

A few students felt that communication skills and reflective learning could not be taught by any 
method, and that motivating people who are not interested in communicating is the problem [51].

Gardner et al. [46] and Gensichen et al. [47] also raised some concerns related to quality - depth and breadth of learning, motivation as well as usability and effectiveness, and this can be seen from the following extract.

The risk of combing for answers to quizzes instead of active, comprehensive learning of information '... if I had a lot of these to do [e-learning learning packages] then I would very likely procrastinate or skim read through them or not pay as much attention because it's not - I'm not necessarily having someone there ... I might do it later or do it at this time,' and it just keeps getting put off' [46].

\section{Theme 8: Lack of IT skills}

Eight out of 24 papers identified the lack of IT or userfriendly IT as one of the key challenges of making elearning successful in HSE [42, 44, 52, 53, 55, 56, 59, 61]. The extract below illustrates this point:

Lack of computer skills has been identified as a major barrier preventing doctors from using computer-based learning methods, rather than a lack of preference for new technologies [52].

Figure 2 is a conceptual framework (CF) that emerged while analysing the findings from those 24 papers. The CF characterised as a step-wise process in a circular flow involving six major components: a) potential influencers, b) institutional barriers or enablers, c) learners or instructors - barriers or enablers, d) delivery mechanisms, e) potential outcomes and f) impact under three broad categories i.e. institutional policy context, instructional design and delivery, and learning outcomes (improve achievements and learning engagement; develop a sense of community). This framework can also be called 'elearning CDDO (context, design, delivery and outcomes) configuration framework' in HSE. This framework has sufficiently mapped the connections between e-learning and its outcomes, reflecting the learning context, potential influencing factors, reported enablers, barriers, and delivery mechanisms associated with instructional design and delivery, and the overall learning outcomes in relation to making el-HSE effective, from the perspective of learners, facilitators and professionals.

The most frequently recorded enablers included individualised and contextual learning, integration of theoretical learning into practice, and interactive, collaborative and flexible learning. The most frequently reported barriers also included course structure, learning space, isolation, poor institutional design, as well as time-, cost- and labourintensive work obligations. Influence of national and international policies, organisational objectives and goals, learning management system, quality, standards and awareness, leadership and financial independence are some of the reported wider influencers. Similarly, increased knowledge, performance, learners' freedom, engagement, and learning contribution to meet the needs of learners' current and future healthcare needs to be described or recorded under the component of outcomes or wider impact. Table 2 provides a summary of factors which emerged from the findings identified about the components of the e-learning conceptual framework in health.

\section{Discussion}

To the best of our knowledge, this is the first systemic literature review examining and synthesising the factors - enablers or barriers - evidencing to e-learning in making HSE effective. In this study, analysing from 24 unique papers, we found that e-learning has some impact on enhancing learning and performance due to the nature of its flexibility and accessibility. Some evidences indicated that e-learning offers to meet lifelong education needs, as well as widening participation in achieving desired learners' outcomes in practice, as e-learning approaches are often context-specific.

There are also opportunities for the provision of online access to learning resources and materials development, as well as some opportunities for collaborating and use of open-source materials [59, 68]. Such collaboration or interaction between learners and facilitators would influence an attitude of sharing knowledge, which is one of the crucial elements of e-learning's shared enterprise $[69,70]$. Gulati [71] further notes that e-learning often takes place through the reflection of workplace learning; therefore it might be viewed as constructivist e-learning. Holmes and Garder [1] referred to it as communal constructivism, arguing that within such a learning context and environment, "each member [learner or facilitator or both] learns with and from others, and contributes learning resources to others".

The study also found that though e-learning facilitates the process of learning and thereby changes in practice by supporting instructional design and delivery mechanisms, which captures the developing of materials using set learning objectives, including teaching strategies embedding feedback and evaluation [30] to influence learners' intrinsic and extrinsic motivation factors, the process has been influenced by several internal, external and contextual factors, including time, IT, flexibility, independence and learners' motivation and expectations $[44,53,55]$.

With reference to medical education, it has been argued that e-learning is primarily meant "to improve the 


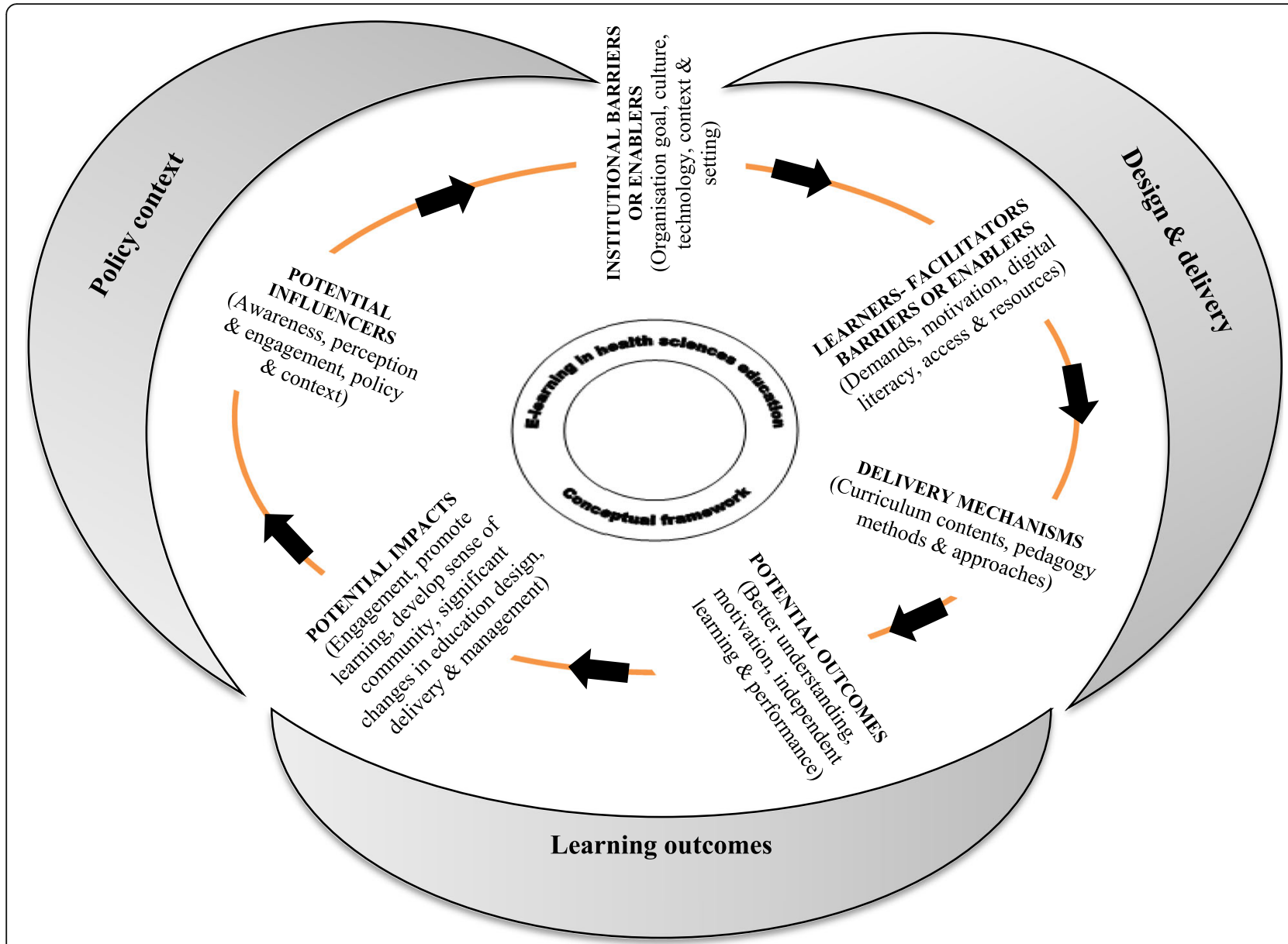

Fig. 2 Conceptual framework of factors influence e-learning in health sciences education

efficiency and effectiveness of educational interventions in the face of the social, scientific, and pedagogic challenges" [22]. Similarly, the study has noted that learning is very much a social phenomenon where interaction and collaboration between learners and tutors embedding feedback and peer support would be an important process that fosters academic dialogue between peers and facilitators [72-74]. As Ramsden [75] argues, "learning is about integrating and understanding reality in a different way". Another interesting point that this study has highlighted is the important role of el-HSE in meeting the demand for "diverse needs of the healthcare employers and individuals by providing education that is flexible, learner-centred, customer-focused", and with individualised learning and styles, including collaboration, costs and integration [76].

This research further explored the importance of utilising user-friendly IT in online teaching and learning, as this can help achieve changes in competence, performance, and outcomes. This review, however, highlighted a number of underlying challenges. In Gilchrist and Ward's [77] view, there are several factors, including appropriate policies and strategies, adequate resources and trained staff in place that might interplay in making e-learning or online education effective. One criticism was that e-learning is often viewed as a technology rather than pedagogy, as it mostly drives learning through technology, compromising the needs and expectations of learners [78]. Another criticism was that, though the effectiveness of e-learning was documented in other studies conducted, it is still difficult to determine the impact because of the variability in instructional designs [32].

One of the greatest threats to improving e-learning is the impacts of education and performance, particularly in relation to successful course delivery, many of which are challenges in HSE [70, 79].

Similarly, as Schmidt and Gallegos [79] highlight, "[s]uccessful conversion of course delivery method is not always guaranteed" as it has several challenges, including quality of contents, IT and the type/nature of e-learning, which has been discussed earlier. Though e-learning or online education has served well in fostering learning through engaging learners as well as sustaining the growth of the education industry for the last few 


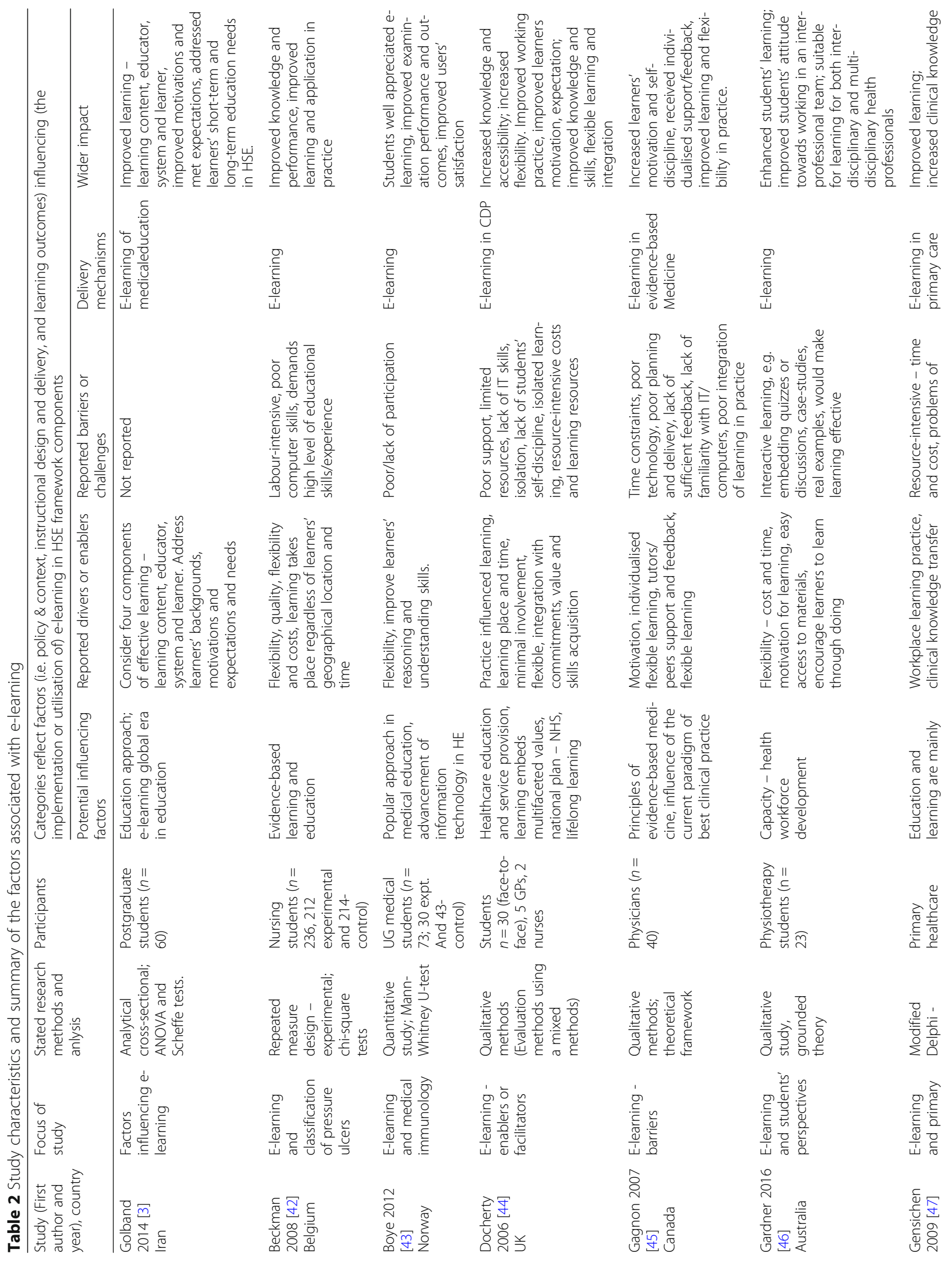




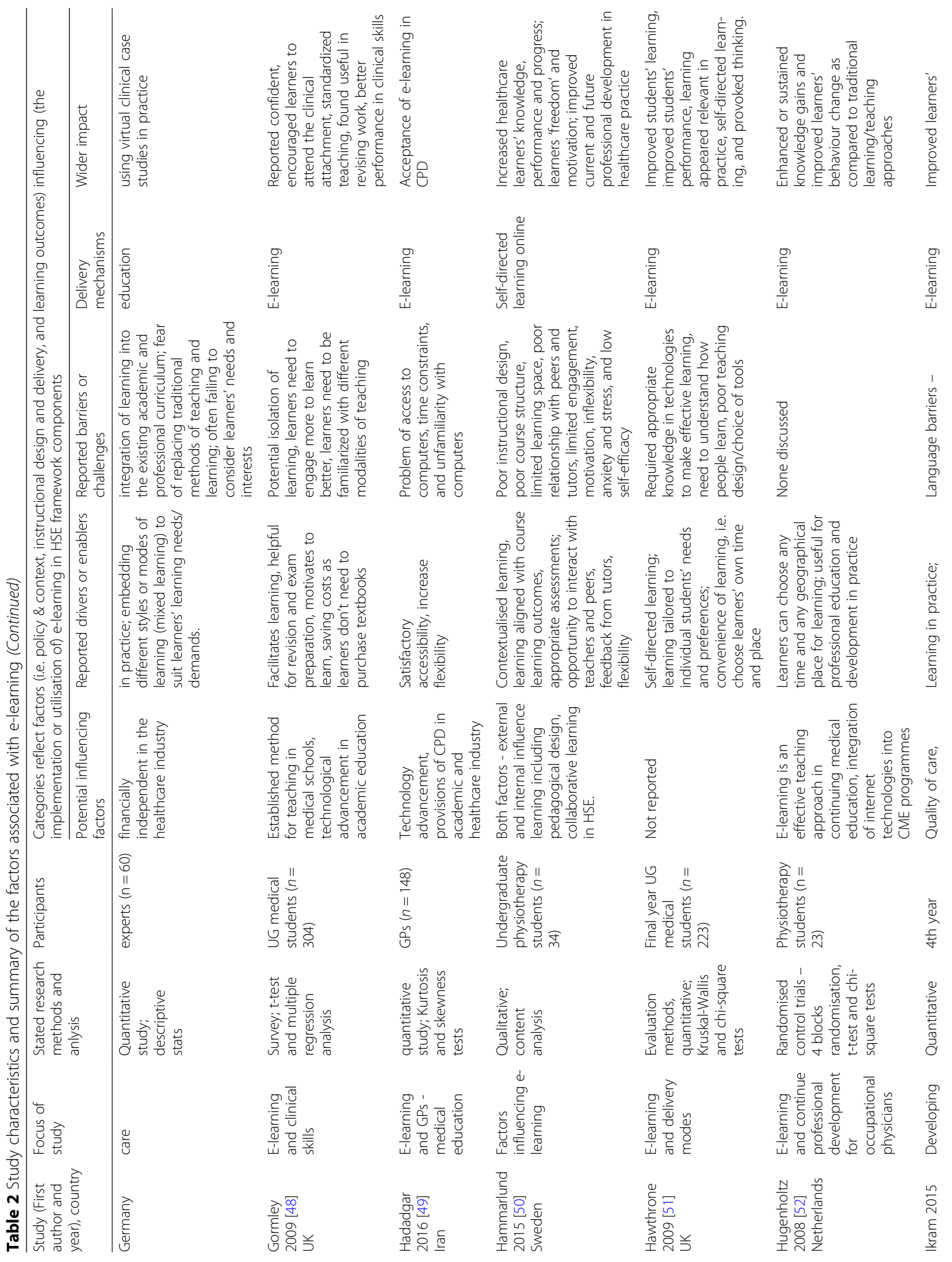




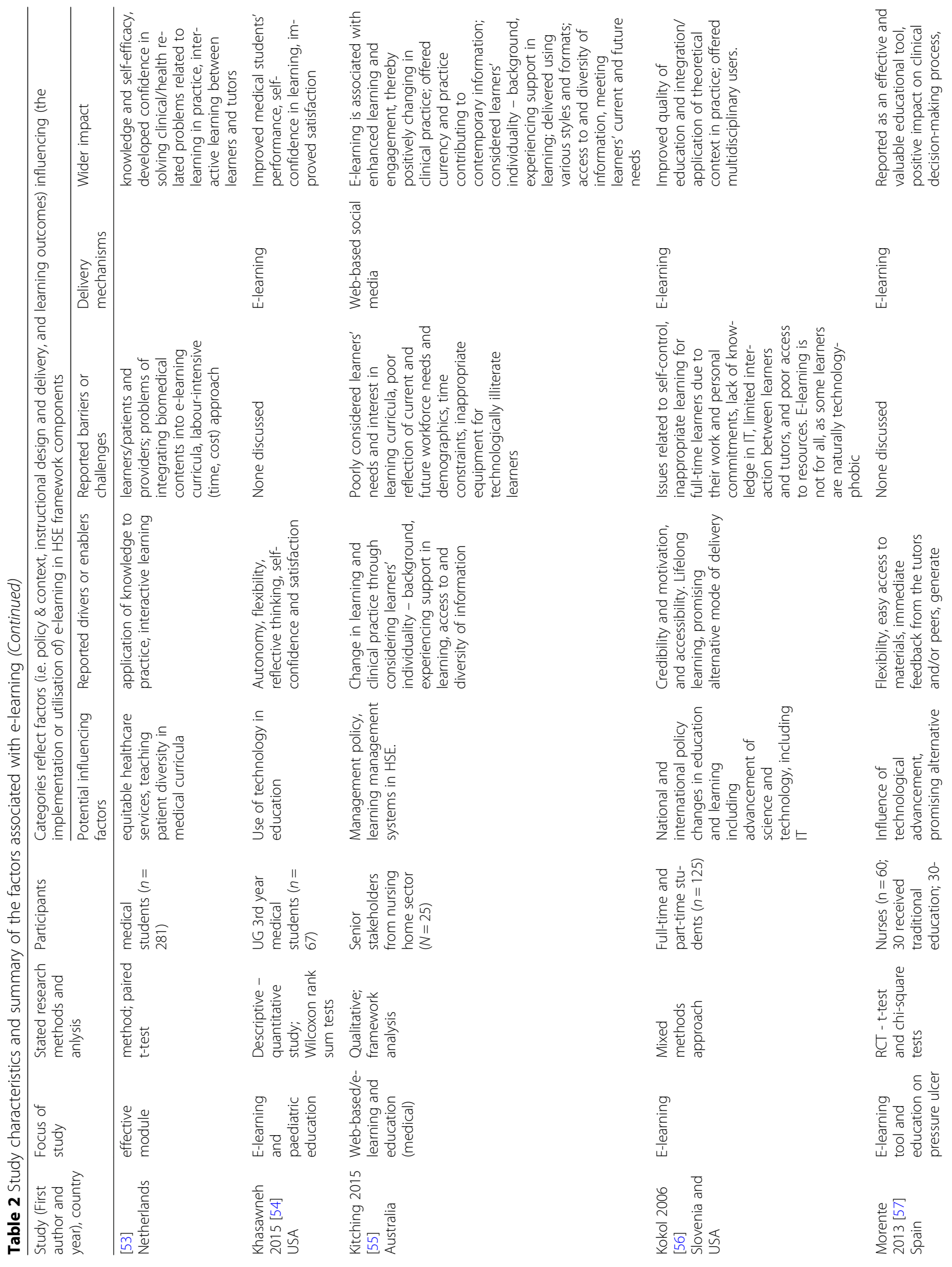




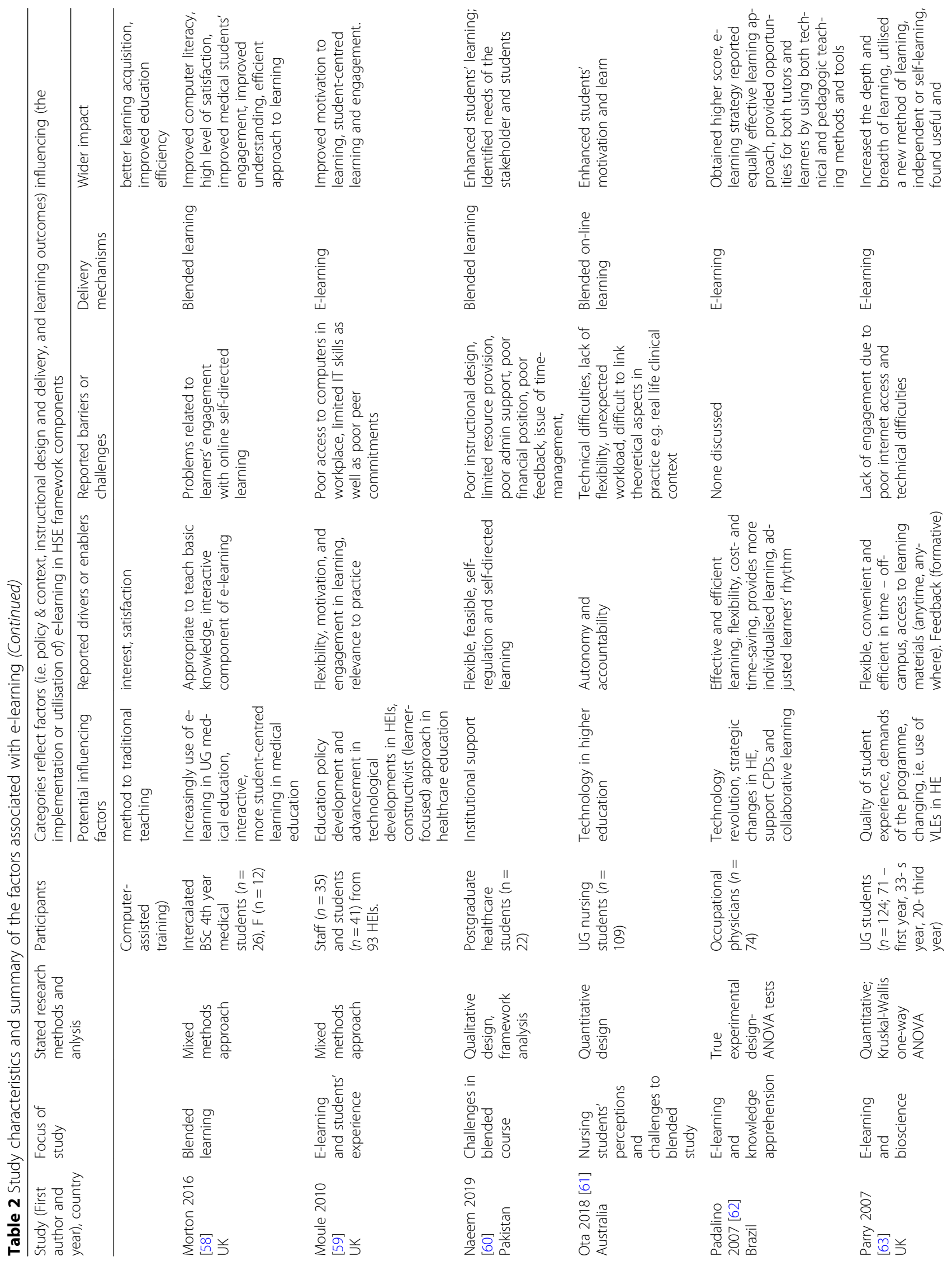




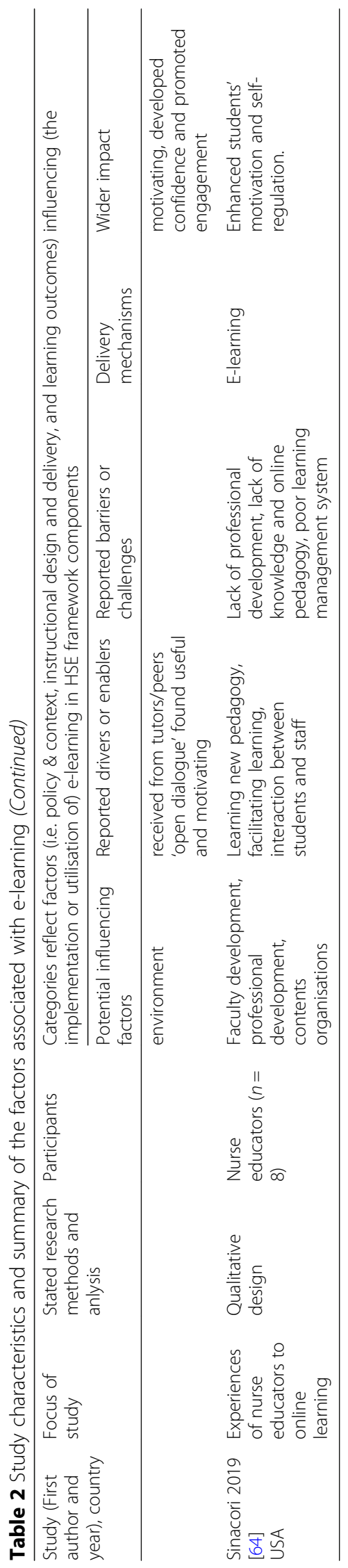


decades, the review noted that the rapid expansion of the approaches in many parts of the world brings another significant challenge $[30,80,81]$. First, some courses by their nature, e.g. biomedicine and engineering, are more theory-driven, where learners demonstrate their learning and performance in the workplace or in practice. In such a context, e-learning may not be an appropriate approach to learning. Second, mostly in clinical research courses, learners need to develop or learn their level of knowledge and skills through trials, e.g. RCTs, where the constant presence of facilitators or tutors is recommended (or sometimes it might be mandatory). Third, faculty and skills development needs of e-learning among staff or facilitators. Finally, there is a lack of inadequate IT facilities in some educational institutions.

This study argues that while in principle, we can equal or even improve on classical/traditional learning methods in terms of quality of education and increasing learners' knowledge achievement [13, 53], in practice, learners or facilitators have to face different challenges or debates [82].

Though the study acknowledged the importance of integrating the strengths of synchronous (face-to-face) and asynchronous (text-based internet) learning activities into curricula using two different models or approaches, e.g. (a) blended learning and (b) flipped classroom to facilitate a simultaneous independent and collaborative learning experience due to its flexible and technologically rich format $[6,7]$, it equally brings a "fundamental reconceptualization and reorganization of the teaching and learning dynamic, starting with various specific contextual needs and contingencies" [7]. Nevertheless, the role of teachers in these models would be crucial, acting as facilitators to support not only students' subject knowledge, but also their acquisition of skills, qualities and competencies [83].

While analysing e-learning models, designs and components [6-8], it has been seen that for online learning, use of electronic communication and techniques unique to computers is a tool, not unlike the telephone, or postal mail, or even the chalkboard, and which should be evaluated or assessed only in the context of the educational design and relevant values deriving from the local political, cultural, professional and social contexts for situated learning [84]. Any educational tools or models can be used well or used poorly considering the values, beliefs and choices - but that is not the fault of the tools or models. Of course, it also depends on the nature and context of the field as well.

The findings of this research have answered the research objectives, which were to systematically gather and synthesise the evidence around e-learning and the factors - enablers and challenges - associated with making HSE effective. These objectives were achieved by demonstrating the aspects of measures or findings in 24 studies (Table 3). Similarly, the conceptual frameworks developed based on the study and components or elements of el-HSE were identified and discussed, and they were sufficiently described or recorded in the 24 studies to demonstrate a clear link between e-learning and its delivery mechanism and potential learning outcomes or impacts (Fig. 2). In that sense, this review study has clearly provided useful information to policy-planners, educators and decision-makers and other stakeholders in terms of the selection of appropriate methods, mechanisms and tools for education and learning [8].

\section{Limitations}

This systematic review has some limitations. First, efforts were undertaken to identify all relevant articles associated with the enablers and barriers related to e-learning with different disciplines in health science education, using seven well-known electronic databases. No grey literature was searched, thus studies could have been missed. Second, we did not contact any author to ask for additional data/relevant studies that may lead to an important source of publication bias. Third, the identified research studies were variable in quality, sample size and study population. Though the overall methodological quality of the included papers was good, the majority of the included papers (17 of 24) failed to describe appropriate detailed descriptions of sample and sampling procedures [3, 42-45, 47-51, 53, 54, 56-59, 63]. About one-third of the studies (seven of 24) provided inadequate descriptions of methodologies $[3,42,47,48,54$, $59,63]$.

Given these methodological weaknesses, these were open to bias. Due to the heterogeneity of data, metaanalysis was not possible to measure the effect size of elearning on health sciences education or the strengths of relationships [85]. Finally, this research study was unfunded, and both time- and resource-limited.

\section{Strengths}

In light of the identified limitations or challenges with robust descriptive literature review data, one of the major strengths of this study was the approach to the literature reviewing/examining from the conceptual framework and its focus on the aspects of making e-learning, in HSE, effective. This study was conducted using a comprehensive search strategy and detailed data extraction method. Similarly, the study has shown that elearning education can help promote lifelong learning and widening participation in achieving desired learner outcomes - embedding national policy and local context, development of appropriate resources, and collaboration and networking with other providers. 
The outcome of this review has revealed several policies and programmatic implications, and the potential benefit could be summarised into two parts: first, this will help learners and facilitators or instructors as well as other stakeholders to better understand the issues related to barriers and/or facilitators associated with elearning, and second, this study will help healthcare education policy-planners and decision-makers understand the conditions or factors that may facilitate or constrain e-learning, so that they would be able to implement elearning policy more effectively in the HSE context. In addition, this study would contribute to developing appropriate policies, guidance and initiatives within the context of theoretical perspectives (education and culture) to confirm or extend the significance of e-learning to establish when, how and where it fits best for making HSE effective.

Though online learning has continued to grow in undergraduate, postgraduate and CPD, there is no doubt that this would need to structure the learning experience to ensure that effective online discourse occurs between the various members of this online discussion (including facilitators, experts, and practitioners) so that the complexity of practice can be grasped and practical solutions proposed, implemented and refined in terms of meeting the emerging competencies [11]]. At the same time, many face-to-face classroom teachers need to learn new knowledge/skills to adapt the current teaching to elearning education [see 25].

\section{Conclusion}

This review explores the potential role of e-learning in general and in HSE in particular, examining the factors - enablers or challenges - using systemic literature review, which has revealed this as a less-studied area of research. The available evidence suggests that making elearning effective in the health sciences is affected not only by the lack of resources - significant time and cost savings and support, but also that design aspects should be taken into account in creating or promoting selfdirected learning. At the same time, appropriate development of institution strategies is paramount. This could include such elements as flexibility and access, learning styles, costs, and integration to promote learners' knowledge and understanding evidence-based national drivers and local contexts, putting learners' learning experience as the main driver, rather than IT, in practice.

The outcome of this review has suggested that el-HSE, both academic and professional, or CPD training and education in the workplace, have the potential to improve learners' level of knowledge and performance through making HSE learning resources accessible to learners or facilitators, regardless of their geographical locations and timescale. This study, therefore, suggests that to bring a positive change in learning and practice, we need to put learners at the centre of learning - considering the pedagogic design, learning styles and their expectations, integrating e-learning into health science education curriculum and practice. Further studies are needed to ensure rigorous study design to deliver quality and effective e-learning, use of technology advancement in healthcare research education for all practising healthcare professionals in education-related randomised controlled trials, and blinding in HSE.

\section{Supplementary information}

Supplementary information accompanies this paper at https://doi.org/10. 1186/s12909-020-02007-6.

Additional file 1. Systematic review protocol.

Additional file 2. Critical appraisal of included studies (QualSyst tools).

Additional file 3. Excluded studies.

\section{Abbreviations}

HSE: Health Sciences Education; SLR: Systemic Literature Review; IT: Information Technology; AMED: Allied \& Complementary Medicine; DHDATA: Department of Health Data; CINAHL: Cumulative Index to Nursing and Allied Health Literature; TA: Thematic Analysis; CPD: Continuing Professional Development; UG: Undergraduate; PG: Postgraduate; RCT: Randomised Controlled Trial; CF: Conceptual Framework

\section{Acknowledgements}

The authors want to thank for all reviewers and their helpful comments. This article is based on research undertaken for a medical education by KR at the University of Dundee, UK.

\section{Authors' contributions}

$K R$ conceived and designed the study with the advice from $\sqcup$; KR and $L J$ reviewed, analysed and interpreted the data and contributed to drafting, revising and finalising the manuscript. All authors read and approved the final version of this manuscript.

\section{Funding}

Not applicable.

Availability of data and materials

All raw data used in this systematic review were extracted from published articles.

\section{Ethics approval and consent to participate}

Ethics approval and consent was not required for this systematic review of the literature.

\section{Consent for publication}

Not applicable.

\section{Competing interests}

The authors declare that they have no competing interests.

Received: 31 October 2019 Accepted: 18 March 2020

Published online: 30 March 2020

References

1. Holmes B, Garder J. E-learning: concepts and practice. London: Sage; 2006.

2. Sandars J. E-learning. In: Walsh A, editor. Oxford textbook of medical education. Oxford: Oxford University Press; 2013. p. 174-85.

3. Golband F, Hosseini AF, Mojtahedzadeh R, Mirhosseini F, Bigdeli S. The correlation between effective factors of e-learning and demographic variables in a post-graduate program of virtual medical education in Tehran University of medical sciences. Acta Med Iran. 2014;52:860-4. 
4. Cook D, Levinson A, Garside S, Dupras D, Erwin P, Montori V. Internet-based learning in the health professions: a meta-analysis. JAMA. 2008;300:1181-96.

5. Ruiz JG, Mintzer MJ, Leipzig RM. The impact of E-learning in medical education. Acad Med. 2006;81:207-12.

6. Algahtani AF. Evaluating the electiveness of the E-learning experience in some universities in Saudi Arabia from male students' perceptions. Durham: Durham University; 2011

7. Garrison DR, Kanuka H. Blended learning: uncovering its transformative potential in higher education. Internet High Educ. 2004;7:95-105.

8. Ruggeri K, Farrington C, Brayne C. A global model for effective use and evaluation of e-learning in health. Telemed J E Health. 2013;19:312-21.

9. Cook D. The research we still are not doing: an agenda for the study of computer based learning. Acad Med. 2005;80:541-8.

10. Childs S, Blenkinsopp E, Hall A, Walton G. Effective e-learning for health professionals and students - barriers and their solutions. A systematic review of the literature - findings from the HeXL project. Health Inf Libr J. 2005:22:20-32.

11. Curran VR, Fleet $L$. A review of evaluation outcomes of web-based continuing medical education. Med Educ. 2005;39:561-7.

12. Donnelly P, Benson J, Kirk P. How to succeed at e-learning. London: BMJ/ Wiley-Blackwell; 2012.

13. McCutcheon K, Lohan M, Traynor M, Martin D. A systematic review evaluating the impact of online or blended learning vs. face-to-face learning of clinical skills in undergraduate nurse education. J Adv Nurs. 2014;71:255-70

14. Wutoh R, Boren SA, Balas EA. E-learning: a review of internet-based continuing medical education. J Contin Educ Heal Prof. 2004;24:20-30.

15. Kim S. The future of e-learning in medical education: current trend and future opportunity. J Contin Educ Health Prof. 2006;3:3. https://doi.org/10. 3352/jeehp.2006.3.3.

16. Means B, Toyama Y, Murphy R, Bakia M, Jones K. Evaluating of evidencebased practices in online learning: a meta-analysis and review of online learning studies. Washington, DC: Centre for Technology in Learning, Department of Education; 2010

17. Cook D, Levinson A, Garside S, Dupras D, Erwin P, Montori V. Instructional design variations in internet-based learning for health professions education: a systematic review and meta-analysis. Acad Med. 2010;85:909-22.

18. Du S, Liu Z, Yin H, Xu G, Zhang H, Wang A. Web-based distance learning for nurse education: a systematic review. Int Nurs Rev. 2013;60:167-77.

19. Lahti $\mathrm{M}$, Hatonen $\mathrm{H}$, Valimaki M. Impact of e-learning on nurses' and student nurses knowledge, skills, and satisfaction: a systematic review and meta-analysis. Int J Nurs Stud. 2014;51:136-49.

20. Vaona A, Banzi R, Kwag KH, Rigon G, Cereda D, Pecoraro V, Tramacere I, Moja L. E-learning for health professionals. Cochrane Database Syst Rev. 2018;1. https://doi.org/10.1002/14651858.CD011736.pub2.

21. Cappel JJ, Hayen RL. Evaluating e-learning: a case study. J Comput Inf Syst. 2004:44:49-56.

22. Ruiz JG, Mintzer MJ, Leipzig RM. The impact of E-learning in medical education. Acad Med. 2006:8:207-12.

23. Al-Shorbaji N, Atun R, Car J, Majeed A, Wheeler E. E-learning for undergraduate health professional education: a systematic review information of health workforce development. Geneva: Imperial College/ WHO; 2015.

24. Fletcher J. Clinical epidemiology notes. What is heterogeneity and is it important? BMJ. 2007;334:94-6.

25. Ellaway R, Masters K. E-learning in medical education. AMEE guide- teaching \& learning, no. 32. Dundee: AMEE; 2008.

26. Walsh K. Blended learning. BMJ. 2005;330:829.

27. den Harder AM, Frijlingh M, Ravesloot CJ, Oosterbaan AE, van der Gijp A. The importance of human-computer interaction in radiology e-learning. J Digital Imagin. 2016;29:195-205.

28. Frehywot $\mathrm{S}$, Vovides $\mathrm{Y}$, Talib Z, Mikhail N, Ross $\mathrm{H}$, Wohltjen $\mathrm{H}$, et al. Elearning in medical education in resource constrained low- and middleincome countries. Hum Resour Health. 2013;11:4. https://doi.org/10.1186/ 1478-4491-11-4

29. Cook DA, McDonald FS. E-learning: is there anything special about the " $e$ ". Perspect Biol Med. 2008;51:5-21.

30. Lewis KO, Cidon MJ, Seto TL, Chen H, Mahan JD. Leveraging e-learning in medical education. Curr Probl Pediatr Adolesc Health Care. 2014;44:150-63.

31. Athanasiou G, Maris N, Apostolakis I. An evaluation of E-learning in healthcare. In: Moumtzoglou A, Kastania A, editors. E-health systems quality and reliability: models and standards. NY: Medical Information Science Reference; 2011. p. 183-203.

32. Bernard R, Abrami P, Lou Y, Borokhovski E. How does distance education compare with classroom instruction? A meta-analysis of the empirical literature. Review Educ Res. 2004;74:379-439.

33. Jwayyed S, Stiffler KA, Wilber ST, Southern A, Weigand J, Bare R, Gerson LW. Technology-assisted education in graduate medical education: a review of the literature. Int J Emerg Med. 2011;4:51-64.

34. Boland A, Cherry M, Dickson R. Doing a systematic review: a student's guide. London: Sage; 2017.

35. Kmet LM, Lee RC, Cook LS. Standard assessment criteria for evaluating primary research papers from a variety of fields. 2004. https://www. biomedcentral.com/content/supplementary/1471-2393-14-52-s2.pdf. Accessed 30 Oct 2019

36. Moher D, Liberati A, Tetzlaff J, Altman DG. The PRISMA group. Preferred reporting items for systematic reviews and meta-analyses: the PRISMA statement. PLoS Med. 2009;6:e1000097. https://doi.org/10.1371/journal. pmed1000097.

37. Clarke M. Overview of methods. In: Webb C, Roe B, editors. Reviewing research evidence for nursing practice: systematic reviews. Oxford: Blackwell Publishing: 2007. p. 3-7.

38. Rodgers M, Sowden A, Petticrew M, Arai L, Roberts H, Britten N, et al. Testing methodological guidance on the conduct of narrative synthesis in systematic reviews. Eval. 2009;15:47-71.

39. Ritchie J, Lewis J, Nicholas CM, Ormston R. Qualitative research practice: a guide for social science student and researchers. London: Sage; 2014

40. Pope C, Ziebland S, Mays N. Qualitative research in health care. Analysing qualitative data. BMJ. 2000:320:114-6.

41. Ritchie J, Spencer L. Qualitative data analysis for applied policy research. In: Bryman A, Burgess R, editors. Analysing qualitative data. London: Routledge; 1994. p. 173-94.

42. Beeckman D, Schoonhoven L. Boucque' H, Maele GV, Defloor T. pressure ulcers: e-learning to improve classification by nurses and nursing students. J Clin Nurs. 2008;17:1697-707.

43. Boye $\mathrm{S}$, Moen T, Vik T. An e-learning course in medical immunology: does it improve learning outcome? Med Teach. 2012;34:9. https://doi.org/10.3109/ $0142159 \times .2012 .675456$.

44. Docherty A, Sandhu H. Student-perceived barriers and facilitators to elearning in continuing professional development in primary care. Educ Prim Care. 2006;17:343-53.

45. Gagnon M, Legare F, Labrecque M, Fremont $P$, Cauchon M, Desmartis MA. Perceived barriers to completing an e-learning program on evidence-based medicine. Inform Prim Care. 2007;15:83-91.

46. Gardner P, Slater H, Jordan JE, Fary RE, Chu J, Briggs AM. Physiotherapy students' perspectives of online e-learning for interdisciplinary management of chronic health conditions: a qualitative study. BMC Med Educ. 2016;16:62.

47. Gensichen J, Vollmar HC, Sönnichsen A, Waldmann U, Sandars J. E-learning for education in primary healthcare- turning the hype into reality: a Delphi study. Eur J Gen Pract. 2009:15:11-4.

48. Gormley GJ, Collins K, Boohan M, Bickle IC, Stevenson M. Is there a place for e-learning in clinical skills? A survey of undergraduate medical students' experiences and attitudes. Med Teach. 2009;31:e6-e12.

49. Hadadgar A, Changiz T, Masiello I, Dehghani Z, Mirshahzadeh N, Zary N. Applicability of the theory of planned behaviour in explaining the general practitioners eLearning use in continuing medical education. BMC Med Edu. 2016;16:215.

50. Hammarlund CS, Nilsson MH, Gummesson C. External and internal factors influencing self-directed online learning of physiotherapy undergraduate students in Sweden: a qualitative study. J Educ Eval Health Prof. 2015:12:33.

51. Hawthorne K, Prout H, Kinnersley P, Houston H. Evaluation of different delivery modes of an interactive e-learning programme for teaching cultural diversity. Patient Edu Couns. 2009;74:5-11.

52. Hugenholtz NI, de Croon EM, Smits PP, van Dijk FJ, Nieuwenhuijsen K. Effectiveness of e-learning in continuing medical education for occupational physicians. Occup Med. 2008;58:370-2.

53. Ikram UZ, Essink-Bot M, Suumond J. How we developed an effective eleaning module for medical students on using professional interpreters. Med Teach. 2015:37:422-7.

54. Khasawneh R, Simonsen K, Snowden J, Higgins J, Beck G. The effectiveness of e-learning in pediatric medical student education. Med Educ Online. 2016;21:29516. 
55. Kitching F, Winbolt M, MacPhail A, Ibrahim JE. Web-based social media for professional medical education: perspectives of senior stakeholders in the nursing home sector. Nurse Educ Today. 2015;35:1192-8.

56. Kokol P, Blazun H, Micetić-Turk D, Abbott PA. E-Learning in nursing education- challenges and opportunities. Stud Health Technol Inform. 2006; 122:387-90.

57. Morente L, Morales-Asencio JM, Veredas FJ. Effectiveness of an e-learning tool for education on pressure ulcer evaluation. J Clin Nurs. 2013;23:2043-52.

58. Morton CE, Saleh SN, Smith SF, Hemani A, Ameen A, Bennie TD. Blended learning: how can we optimise undergraduate student engagement? BMC Med Educ. 2016;16:195.

59. Moule P, Ward R, Lockyer L. Nursing and healthcare students' experiences and use of e-learning in higher education. J Adv Nurs. 2010;66:2785-95.

60. Naeem NK, Khan RA. Stuck in the blend: challenges faced by students enrolled in blended programs of Masters in health professions education. Pak J Med Sci. 2019;35:929-33.

61. Ota M, Peck B, Porter J. Evlating a blended online learning model among undergraduate nursing studies: a qualitative study. Comput Inform Nurs. 2018:35:507-12

62. Paladino Y, Peres HH. E-learning: a comparative study for knowledge apprehension among nurses. Rev Lat Am Enfermagem. 2007;15:397-403.

63. Parry D, Larsen C, Marwood C, Walsh C. Realising e-learning matters in a bioscience cohort. Bioscience Educ. 2007;10:1-10.

64. Sinacori BC. How nurse educators perceive the transition from the traditional classroom to the online environment a qualitative inquiry. Nurs Educ Perspect. 2019. https://doi.org/10.1097/01.NEP.0000000000000490.

65. Petticrew M, Roberts $H$. Systematic reviews in the social sciences: a practical guide. Oxford: Blackwell Publishing; 2006.

66. Lee L, Packer TL, Tang SH, Girdler S. Self-management education programs for age-related macular degeneration: a systematic review. Australas J Ageing. 2008;27:170-6.

67. Maharaj S, Harding R. The needs, models of care, interventions and outcomes of palliative care in the Caribbean: a systematic review of the evidence. BMC Palliat Care. 2016;15:9. https://doi.org/10.1186/s12904-016-0079-6.

68. Rice S, McKendree J. E-learning. In: Swanwick T, editor. Understanding medical education. Oxford: Association for the Study of Medical Education and Wiley Blackwell; 2014. p. 161-74.

69. Levy Y. Assessing the value of e-learning systems. Hershey: Information Science Publishing; 2006.

70. Moule P, Ward R, Shepherd K, Lockyer L, Almeida C. Scoping e-learning: use and development in health sciences and practice. Project report. London: Higher Education and Academy; 2008.

71. Gulati S. Application of new technologies: nurse education. In: Glen S, Moule P, editors. E-learning in nursing. Basingstoke: Palgrave; 2006. p. 20-37.

72. Jungert T, Rosander M. Self-efficacy and strategies to influence the study environment. Teach High Educ. 2010;15:647-59.

73. Kropf C. Connectivism: 21st century's new learning theory. Eur J Open Distance E-Learning. 2013;16:13-24.

74. Reeves PM, Reeves TC. Design considerations for online learning in health and social work education. Learn Health Soc Care. 2008;7:46-58.

75. Ramsden P. Learning to teach in higher education. London: Routledge; 1992.

76. Ayer S, Smith C. Planning flexible learning to match the needs of customers: a national survey. J Adv Nurs. 1998;27:1034-47.

77. Gilchrist M, Ward R. Facilitating access to online learning. In: Glen S, Moule P, editors. E-learning in nursing. Basingstoke: Palgrave; 2006. p. 93-111.

78. Higher Education Funding Council for England. Enhancing learning and teaching through the use of technology: a revised approach to HEFCE's strategy for e-learning. 2009. http://webarchive.nationalarchives.gov.uk/201 00202100434/http://www.hefce.ac.uk/pubs/hefce/2009/09_12/09_12.pdf. Accessed 31 Oct 2019.

79. Schmidt E, Gallegos A. Distance learning: issues and concerns of distance learners. J Ind Technol. 2001;17:1-5.

80. Chumley-Jones HS, Dobbie A, Alford CL. Web-based learning: sound educational method or hype? A review of the evaluation literature. Acad Med. 2002;77(10 Suppl):S86-93

81. Gibbons A, Fairweather P. Computer-based instruction. In: Tobias S, Fletcher J, editors. Training \& retraining: a handbook for business, industry, government, and the military. New York: Macmillan Reference; 2000. p. 410-42.

82. Kim K, Bonk C. The future of online teaching and learning in higher education: the survey says. Educ Q. 2006;4:22-30.
83. Capone, R, De Caterina P, Mazza G. Blended learning, flipped classroom and virtual environment: challenges and opportunities for the 21st century students. Conference paper July 2017 DOl: https://doi.org/10.21125/ edulearn.2017.0985. Proceedings of EDULEARN17 conference, 3rd-5th July 2017, Barcelona, Spain; 2017.

84. Grant J. Principles of curriculum design. In: Swanwick T, editor. Understanding medical education: evidence, theory and practice. Chichester: Wiley; 2006. p. 31-46.

85. Higgins JP, Green S. Cochrane handbook for systematic reviews for interventions. West Sussex: Wiley; 2008.

\section{Publisher's Note}

Springer Nature remains neutral with regard to jurisdictional claims in published maps and institutional affiliations.
Ready to submit your research? Choose BMC and benefit from:

- fast, convenient online submission

- thorough peer review by experienced researchers in your field

- rapid publication on acceptance

- support for research data, including large and complex data types

- gold Open Access which fosters wider collaboration and increased citations

- maximum visibility for your research: over $100 \mathrm{M}$ website views per year

At BMC, research is always in progress.

Learn more biomedcentral.com/submissions 